\title{
PENINGKATAN PELAKSANAAN LANGKAH-LANGKAH MENUJU KESELAMATAN PASIEN MELALUI PROSES PEMBERIAN ASUHAN KEPERAWATAN
}

\author{
Erta Iman Jelita Harefa/181101138 \\ ertahrf08@gmail.com
}

\begin{abstract}
Abstrak
Latar belakang: Pada era global saat ini tuntutan pelayanan kesehatan termasuk pelayanan keperawatan yang profesional dengan standar internasional. Pelayanan kesehatan tidak lagi hanya berfokus pada kepuasan pasien tetapi juga lebih berfokus mengenai keselamatan pasien (patient safety). Keselamatan pasien telah menjadi isu global yang sangat penting dilaksanakan oleh setiap rumah sakit dan seharusnya menjadi prioritas utama untuk dilaksanakan dan hal tersebut terkait dengan mutu dan citra rumah sakit. Sehingga hal ini dapat dihindarkan dengan melakukan beberapa langkah-langkah menuju keselamatan pasien yang akan dilaksanakan oleh para tenaga kesehatan.

Tujuan: penulisan ini bertujuan untuk mengetahui dan memberi informasi tentang peningkatan pelaksanaan langkah-langkah menuju keselamatan pasien melalui proses pemberian asuhan keperawatan.

Metode: Penulisan ini menggunakan metode literature review dengan pendekatan jurnal atau artikel, buku dan e-book yang relevan dan akurat serta berfokus pada peningkatan pelaksanaan langkah-langkah menuju keselamatan pasien melalui proses pemberian asuhan keperawatan dengan menggunakan Google Scholar, Portal Garuda, dan Jurnal Keperawatan Indonesia.

Hasil: Berdasarkan hasil pencarian literatur terdapat 7 langkah-langkah menuju keselamatan pasien yang memberikan pelayanan berkualitas dan bermutu tinggi.

Pembahasan: Dalam melaksanakan keselamatan pasien dibutuhkan kualitas perawatan yang berkualitas tinggi. Untuk mencapai kualitas yang tinggi di perlukan para tenaga kesehatan dalam menjalankannya dan salah satu tenaga kesehatan yang setiap hari berhubungan atau memberikan perawatan kepada pasien/klien adalah perawat. Dalam hal ini perawat memberikan pelayanan dalam bentuk asuhan keperawatan.

Penutup: peningkatan pelaksanaan keselamatan pasien dari Peraturan Menteri Kesehatan Republik Indonesia No. 1691 Tahun 2011 tentang keselamatan pasien rumah sakit dan Peraturan Menteri Kesehatan Republik Indonesia No. 11 Tahun 2017 tentang keselamatan pasien.
\end{abstract}

Kata kunci: peningkatan, langkah-langkah menuju keselamatan pasien, asuhan keperawatan 


\section{LATAR BELAKANG}

Pada era global saat ini tuntutan pelayanan kesehatan termasuk pelayanan keperawatan yang profesional dengan standar internasional. Pelayanan kesehatan tidak lagi hanya berfokus pada kepuasan pasien tetapi juga lebih berfokus mengenai keselamatan pasien (patient safety). Keselamatan pasien sudah menjadi masalah yang sangat penting dilaksanakan oleh setiap rumah sakit dan seharusnya menjadi hal utama untuk dilaksanakan dan hal tersebut terkait dengan mutu dan citra rumah sakit.

Keselamatan pasien merupakan hal yang harus diperhatikan oleh tenaga kesehatan saat memberikan pelayanan kesehatan kepada pasien. Dalam keselamatan pasien terdapat masalah utama dalam upaya implementasi yang terdiri dari insiden keselamatan pasien (IKP) dalam pelayanan kesehatan di rumah sakit. Insiden keselamatan pasien ini meliputi kejadian tidak diharapkan (KTD), kejadian nyaris cidera (KNC), kondisi potensial cidera (KPC) dan kejadian sentinel dalam proses asuhan pelayanan medis maupun asuhan pelayanan keperawatan dari yang ringan sampai yang berat.
Setiap tindakan pelayanan kesehatan yang diberikan kepada pasien sudah seharusnya memberi dampak positif dan tidak memberikan kerugian bagi pasien. Oleh karena itu, rumah sakit memiliki standar tertentu dalam memberikan pelayanan kesehatan kepada pasien. Kesalahan dalam penanganan pasien yang justru merugikan pasien sejauh mungkin harus dihindari baik yang dilakukan oleh dokter, perawat, serta petugas rumah sakit lain. Untuk itu pasien dan keluarganya membutuhkan suatu jaminan hukum bagi penanganan petugas rumah sakit. Sehingga hal-hal penanganan pasien diluar standar sejauh mungkin bisa dihindarkan (Wahyati, 2012).

World Health Organization (WHO) juga telah menegaskan pentingnya keselamatan dalam pelayanan kepada pasien: "Safety is a fundamental principle of patient care and a critical component of quality management." Sehubungan dengan data Kejadian Tidak Diharapkan (KTD) di rumah sakit diberbagai negara menunjukkan angka 3-16\% yang tidak kecil (WHO, 2004).

Dirumah sakit terdapat ribuan jenis obat, ratusan tes dan prosedur, banyak alat dengan teknologinya, bermacam jenis tenaga profesi dan non profesi yang siap 
memberikan pelayanan pasien 24 jam secara berulang. Keberagaman dan kerutinan tersebut apabila tidak dikelola dengan baik dapat terjadi KTD (Depkes RI, 2006). Sehingga hal ini dapat dihindarkan dengan melakukan beberapa langkah-langkah menuju keselamatan pasien yang akan dilaksanakan oleh para tenaga kesehatan. Para tenaga kesehatan yang lebih dominan dalam memberikan pelayanan kesehatan kepada pasien adalah tenaga perawat dikarenakan memiliki kedudukan penting dalam menghasilkan kualitas pelayanan yang diberikan berdasarkan pendekatan biopsikososial dan spiritual. Tenaga perawat memberikan pelayanannya dalam bentuk asuhan keperawatan. Asuhan keperawatan adalah keseluruhan proses keperawatan yang diberikan kepada pasien yang berkesinambungan dengan di mulai dari pengkajian sampai dengan evaluasi dalam usaha memperbaiki ataupun memelihara derajat kesehatan yang optimal.

\section{TUJUAN}

Tujuan penulisan ini adalah untuk mengetahui dan memberi informasi tentang peningkatan pelaksanaan langkah-langkah menuju keselamatan pasien melalui proses pemberian asuhan keperawatan.

\section{METODE}

Penulisan ini menggunakan metode literature review dengan pendekatan jurnal atau artikel, buku dan e-book yang relevan dan akurat serta berfokus pada peningkatan pelaksanaan langkahlangkah menuju keselamatan pasien melalui proses pemberian asuhan keperawatan. Adapun jurnal atau artikel dan e-book yang digunakan pada literature review adalah jurnal atau artikel dan e-book yang didapatkan dengan menggunakan Google Scholar, Portal Garuda, dan Jurnal Keperawatan Indonesia.

\section{HASIL}

Berdasarkan hasil pencarian literatur di dapatkan beberapa langkah-langkah menuju keselamatan pasien sebagai berikut:

1. Membangun Kesadaran Akan Nilai Keselamatan

Dalam hal ini dilakukan untuk menciptakan kepemimpinan dan budaya yang terbuka dan adil. Langkah-langkah penerapannya sebagai berikut:

a) Untuk Tingkat Fasilitas Pelayanan Kesehatan 
Dalam hal ini harus memastikan terdapat adanya kebijakan yang harus dilakukan oleh staf apabila terjadi insiden, cara melakukan investigasi, dan cara memberikan dukungan kepada pasien, keluarga, dan staf; memastikan bahwa kebijakan memiliki kejelasan tentang individu dan akuntabilitasnya bila terjadi insiden serta melakukan survei budaya keselamatan untuk menilai budaya pelaporan dan pembelajaran di fasilitas pelayanan kesehatan.

b) Untuk Tingkat Unit/Pelaksana

Disini perlu memastikan sesama teman dalam kemampuan berbicara tentang pendapatnya dan membuat laporan apabila terjadi insiden serta menunjukkan kepada tim tentang tindakan-tindakan yang sudah dilakukan oleh fasilitas pelayanan kesehatan dalam menindak lanjuti laporan-laporan secara adil guna pembelajaran dan pengambilan keputusan yang tepat.

2. Memimpin Dan Mendukung Staf Membangun komitmen dan fokus yang kuat dan jelas tentang keselamatan pasien di rumah sakit. Langkah-langkah penerapannya sebagai berikut:
a) Untuk Tingkat Fasilitas Pelayanan Kesehatan

Dalam hal ini memastikan adanya anggota direksi atau pimpinan yang bertanggungjawab atas keselamatan pasien, mengidentifikasi setiap bagian di rumah sakit mengenai orang-orang yang diandalkan untuk menjadi penggerak dalam gerakan keselamatan pasien, dan memprioritaskan keselamatan pasien dalam agenda rapat direksi maupun rapat manajemen rumah sakit serta memasukkan keselamatan pasien dalam semua program latihan staf rumah sakit.

b) Untuk Tingkat Unit/Pelaksana

Disini di perlukan calon penggerak untuk keselamatan pasien, dan menjelaskan pentingnya keselamatan pasien kepada anggota unit dan menumbuhkan sikap ksatria yang menghargai pelaporan insiden.
3. Mengintegrasikan
Aktivitas
Pengelolaan Risiko
Mengembangkan sistem dan proses pengelolaan risiko serta melakukan identifikasi dan asesmen hal yang potensial bermasalah. Langkah-langkah penerapannya sebagai berikut: 
a) Untuk Tingkat Fasilitas Pelayanan Kesehatan

Mempelajari kembali struktur dan proses dalam pengelolaan risiko klinis maupun non klinis serta memastikan hal tersebut mecakup dan terintegrasi dengan keselamatan pasien dan staf serta mengembangkan indikatorindikator kinerja untuk sistem manajemen risiko sehingga dapat di monitor oleh pimpinan dan menggunakan informasi-informasi yang diperoleh dari sistem pelaporan insiden sebagai perbaikan pelayanan pasien.

b) Untuk Tingkat Unit/Pelaksana

Membentuk forum-forum dalam rumah sakit untuk mendiskusikan isuisu keselamatan pasien guna memberikan umpan balik kepada manajemen yang terkait dan memastikan adanya penilaian risiko pada individu pasien dalam proses asesmen risiko secara teratur untuk menentukan akseptabilitas setiap risiko dan mengambil langkahlangkah yang tepat.

4. Mengembangkan Sistem Pelaporan Memastikan staf dapat melaporkan kejadian/insiden serta rumah sakit mengatur pelaporan kepada Komite Nasional Keselamatan Pasien Rumah
Sakit. Langkah-langkah penerapannya sebagai berikut:

a) Untuk Tingkat Fasilitas Pelayanan Kesehatan

Membangun dan melengkapi rencana implementasi sistem pelaporan insiden ke dalam maupun ke luar yang harus dilaporkan ke Komite Nasional Keselamatan Pasien (KNKP) Rumah Sakit.

b) Untuk Tingkat Unit/Pelaksana Memberikan semangat kepada rekan sekerja untuk secara aktif melaporkan setiap insiden yang terjadi dan insiden yang telah dicegah karena mengandung bahan pelajaran yang penting.

5. Melibatkan Dan Berkomunikasi Dengan Pasien

Mengembangkan cara-cara komunikasi yang terbuka dengan pasien. Langkahlangkah penerapannya sebagai berikut:

a) Untuk Tingkat Fasilitas Pelayanan Kesehatan

Mengembangkan kebijakan yang mencakup komunikasi terbuka dengan pasien dan keluarganya tentang insiden yang terjadi dan memastikan mendapatkan informasi apabila terjadi insiden serta memberikan dukungan kepada staf dalam melakukan pelatihan-pelatihan yang mampu 
melaksanakan keterbukaan kepada pasien dan keluarganya.

b) Untuk Tingkat Unit/Pelaksana Memastikan anggota tim menghargai dan mendukung keterlibatan pasien dan keluarganya secara aktif waktu terjadi insiden dan memprioritaskan kebutuhan untuk memberikan informasi kepada pasien dan keluarganya waktu terjadinya insiden secara jelas, akurat, dan tepat waktu serta menunjukkan rasa empati.

6. Belajar Dan Berbagi Pengalaman Tentang Keselamatan Pasien

Mendorong staf untuk melakukan analisis akar masalah untuk belajar bagaimana dan mengapa kejadian itu timbul. Langkah-langkah penerapannya sebagai berikut:

a) Untuk Tingkat Fasilitas Pelayanan Kesehatan

Menyakinkan staf yang sudah terlatih melakukan investigasi insiden secara tepat sehingga bisa mengidentifikasi akar masalah dan mengembangkan kebijakan yang mencakup kriteria fasilitas pelayanan kesehatan harus melakukan Root Cause Analysis (RCA).

b) Untuk Tingkat Unit/Pelaksana Melakukan pembelajaran di dalam lingkup unit dari analisa insiden keselamatan pasien dan mengidentifikasi unit lain yang mungkin terkena dampak di masa depan dan berbagilah pengalaman secara lebih luas.

7. Mencegah Cedera Melalui Implementasi Sistem Keselamatan Pasien

a) Untuk Tingkat Fasilitas Pelayanan Kesehatan

Menggunakan informasi yang benar dan jelas yang diperoleh dari sistem pelaporan, asesmen risiko, kajian insiden, dan analisis untuk menentukan solusi setempat. Hal ini mencakup penjabaran ulang sistem dan penyesuaian staf atau kegiatan klinis untuk mensosialisasikan solusi yang akan dikembangkan oleh Komite Nasional Keselamatan Pasien Rumah Sakit serta memberikan umpan balik kepada staf tentang setiap tindakan yang diambil atas insiden yang dilaporkan.

b) Untuk Tingkat Unit/Pelaksana Melibatkan tim dalam pengembangan cara-cara agar asuhan pasien lebih baik dan aman serta mengkaji ulang perubahan-perubahan yang sudah dibuat dengan tim dan memastikan tim menerima feedback pada setiap followup dalam pelaporan insiden. 


\section{PEMBAHASAN}

Menurut Vincent (2008), keselamatan pasien merupakan sebagai penghindaran, pencegahan dan perbaikan dari hasil tindakan yang buruk atau injuri yang berasal dari proses perawatan kesehatan. Dalam perawatan kesehatan, perbaikan yang pertama kali yang harus dilakukan mengacu pada kebutuhan akan intervensi medis yang cepat untuk mengatasi krisis segera dan untuk merawat pasien dengan injuri dan untuk mendukung staf yang terlibat. Dalam melaksanakan keselamatan pasien dibutuhkan dan diperlukan kualitas perawatan yang berkualitas tinggi. Untuk mencapai kualitas yang tinggi di perlukan para tenaga kesehatan dalam menjalankannya dan salah satu tenaga kesehatan yang setiap hari berhubungan atau memberikan perawatan kepada pasien/klien adalah perawat. Dalam hal ini perawat memberikan pelayanan dalam bentuk asuhan keperawatan.

Asuhan keperawatan merupakan proses atau rangkaian kegiatan pada praktik keperawatan yang diberikan secara langsung pada pasien/klien di berbagai tatanan pelayanan kesehatan. Asuhan keperawatan bertujuan untuk membantu individu untuk mandiri, mengajak individu atau masyarakat berpartisipasi dalam bidang kesehatan, membantu individu mengembangkan potensi untuk memelihara kesehatan secara optimal agar tidak tergantung pada orang lain dalam memelihara kesehatan dan membantu individu memperoleh derajat kesehatan yang optimal.

Untuk itu setiap perawat dalam memberikan asuhan keperawatan kepada pasien/klien harus mengutamakan dan memprioritaskan pentingnya keselamatan pasien sebab keselamatan pasien menjadi hal yang terpenting dalam segala proses perawatan yang akan dilakukan maupun yang tidak dilakukan.

Dalam pelaksanaan keselamatan pasien dapat dilihat dari Peraturan Menteri Kesehatan Republik Indonesia No. 1691 Tahun 2011 tentang keselamatan pasien rumah sakit dan Peraturan Menteri Kesehatan Republik Indonesia No. 11 Tahun 2017 tentang keselamatan pasien. Dari hasil pencarian literatur yang telah dijabarkan diatas terdapat beberapa kegiatan yang dilaksanakan dalam pelaksanaan langkah-langkah menuju keselamatan pasien sebagai berikut:
A. Di rumah sakit
1) Membentuk Tim Keselamatan Pasien
Rumah Sakit (TKPRS) dengan susunan 
organisasi yang terdiri dari ketua: dokter dan anggota pelaksanaan: dokter, dokter gigi, perawat, tenaga kefarmasian dan tenaga kesehatan lainnya; 2) Mengembangkan sistem informasi pencatatan dan pelaporan internal tentang insiden; 3) Melakukan pelaporan insiden ke Komite Keselamatan Pasien Rumah Sakit (KKPRS) secara rahasia; 4) Mengembangkan standar pelayanan medis berdasarkan hasil dari analisis akar masalah dan sebagai tempat pelatihan standar-standar yang baru dikembangkan.

B. Di Provinsi/Kota/ Kabupaten

1) Melakukan advokasi program keselamatan pasien ke rumah sakitrumah sakit di wilayahnya; 2) Melakukan advokasi ke pemerintahan daerah agar tersedianya dukungan anggaran terkait dengan program keselamatan pasien rumah sakit; 3) Melakukan pembinaan pelaksanaan program keselamatan pasien rumah sakit.

C. Di pusat

1) Membentuk Komite Keselamatan Pasien Rumah Sakit dibawah Perhimpunan Rumah Sakit Seluruh Indonesia; 2) Menyusun panduan nasional tentang Keselamatan Pasien Rumah Sakit; 3) Melakukan sosialisasi dan advokasi program keselamatan pasien ke Dinas Kesehatan Provinsi/Kota/Kabupaten, PERSI daerah dan rumah sakit pendidikan dengan jejaring pendidikan; 4) Mengembangkan laboratorium uji coba program keselamatan pasien.

\section{PENUTUP}

Keselamatan pasien merupakan hal mendasar yang perlu diperhatikan oleh tenaga medis saat memberikan pelayanan kesehatan kepada pasien. Keselamatan pasien adalah suatu sistem dimana rumah sakit memberikan asuhan kepada pasien secara aman serta mencegah terjadinya cidera akibat kesalahan karena melaksanakan suatu tindakan atau tidak melaksanakan suatu tindakan yang seharusnya diambil. Dalam hal ini dapat diketahui peningkatan pelaksanaan keselamatan pasien dari Peraturan Menteri Kesehatan Republik Indonesia No. 1691 Tahun 2011 tentang keselamatan pasien rumah sakit dan Peraturan Menteri Kesehatan Republik Indonesia No. 11 Tahun 2017 tentang keselamatan pasien. 


\section{REFERENSI}

Achmadi, L. D. L., Pondaag, L., Babakal, A. (2015). Gambaran Tingkat Pelaksanaan Pengetahuan Perawat Dalam Penerapan Standar Asuhan Keperawatan di Ruang Rawat Inap Interna RSUD Datoe Bhinangkang. E-Journal Keperawatan, Vol. 3, No. 3.

Departemen Kesehatan RI. (2008).

Panduan Nasional Keselamatan Pasien Rumah Sakit (Patient Safety). Jakarta: Depkes RI.

Departemen Kesehatan RI. (2008).

Upaya Peningkatan Mutu

Pelayanan Rumah Sakit. Jakarta:

Depkes RI.

Fitriana, Y., Pratiwi, K. (2018).

Pelaksanaaan Patient Safety di Rumah Sakit Umum Daerah dan

Rumah Sakit Umum Swasta

Bantul Berdasarkan Ketentuan Undang-Undang Nomor 44 Tahun 2009 Tentang Rumah Sakit. Jurnal Kebidanan, 7 (1).

Hakim, L., Pudjirahardjo, W. J. (2014). Optimalisasi Proses Koordinasi Program Keselamatan Pasien (Patient Safety) di Rumah Sakit X Surabaya. Jurnal Administrasi
Kesehatan Indonesia, Vol. 2, No.

3.

Iskandar, Edi. (2017). Tata Kelola dan Kepatuhan Penerapan Standar Patient Safety Penyakit Stroke di Rumah Sakit Dr. Kanujoso Djatiwibowo Tahun 2005. Jurnal ARSI, 169-174.

Ismainar, Hetty. (2015). Keselamatan Pasien di Rumah Sakit. Yogyakarta: Deepublish.

Kamil, H. (2010). Patient Safety. Idea Nursing Journal, 1-8.

Mulyati, L., Rachman, D., Herdiana, Y. (2016). Faktor Determinan Yang Mempengaruhi Budaya Keselamatan Pasien di RS Pemerintah Kabupaten Kuningan. Jurnal Keperawatan, Vol. 4, No. 2.

Permenkes RI. (2011). Peraturan Menteri Kesehatan Republik Indonesia Nomor 1691/Menkes/Per/VIII/2011

Tentang Keselamatan Pasien Rumah Sakit. Jakarta: Depkes RI. Permenkes RI. (2017). Peraturan Menteri Kesehatan Republik Indonesia Nomor 11 Tahun 2017 Tentang Keselamatan Pasien. Jakarta: Depkes RI. 
Simamora, R. H. (2019). Buku Ajar Pelaksanaan Identifikasi Pasien. Uwais Inspirasi Indonesia.

Simamora, R. H. (2019). Documentation of Patient Identification Into The Electronic System to Improve The Quality of Nursing Services. International Journal of Scientific \& Technology Research.

Simamora, R. H. (2019). The Influence of Training Handover Based SBAR Communication for Improving Patients Safety. Indian Journal of Public Health Research \& Development.

Tutiany, Lindawati, Krisanti P. (2017).

Bahan Ajar Keperawatan: Manajemen Keselamatan Pasien. Jakarta: Kemenkes RI.

Utarini, A., Djasri, H. (2012). Keselamatan Pasien dan Mutu Pelayanan Kesehatan. Jurnal Manajemen Pelayanan Kesehatan, 159-160.

Wardhani, Viera. (2017). Buku Ajar Manajemen Keselamatan Pasien. Malang: UB Press. 